\title{
Blunt Hepatic Trauma: Suggested Algorithm for Surgical and Nonoperative Management
}

\author{
${ }^{1}$ Camila Issa Azevedo, ${ }^{2}$ Aparecida Andrade Ribeiro Franciscani, ${ }^{3}$ Amanda Baraldi Souza \\ ${ }^{4}$ Fabio Mendes Botelho Filho, ${ }^{5}$ Sizenando Vieira Starling, ${ }^{6}$ Domingos André Fernandes Drumond
}

\begin{abstract}
Objective: This study aims to analyze the outcomes of blunt hepatic trauma, and compare operative treatment (OT) and nonoperative management (NOM) emphasizing the stratified results by grade of injury and failure rate.
\end{abstract}

Materials and methods: This is a prospective study of cases admitted to João XXIII Hospital, located in Belo Horizonte, Brazil, from January 2013 to December 2013. Patients were admitted with blunt hepatic trauma on emergency room (ER) and were divided into two groups. One group contained patients who met the criteria for NOM, and the other group was formed by patients with surgical indication.

Results: During the study period, 47 patients were admitted with blunt liver injury and $43(91.4 \%)$ met the inclusion criteria for NOM. The rate of NOM failure was $9.3 \%$ : $50 \%$ of them had grade II injury and $50 \%$ had grade $\mathrm{V}$. The patients with grade II injury had also extrahepatic lesions and, in those with grade $\mathrm{V}$, the failure was due to bleeding.

Conclusion: Nonoperative management has become the standard of care for patients with blunt liver injuries in trauma centers. However, as grade $\mathrm{V}$ injuries have a higher failure rate, they might receive special attention from the surgical team.

Keywords: Liver, Wounds, Wounds and injuries, Nonoperative, Laparotomy.

How to cite this article: Azevedo $\mathrm{Cl}$, Franciscani AAR, Souza AB, Filho FMB, Starling SV, Drumond DAF. Blunt Hepatic Trauma: Suggested Algorithm for Surgical and Nonoperative Management. Panam J Trauma Crit Care Emerg Surg 2015;4(1):1-5.

Source of support: Nil

Conflict of interest: None

\section{RESUMEN}

Objetivo: Analizar la evolución del trauma hepático cerrado sometidos a tratamiento operatorio (TO) y no operatorio (TNO), dando énfasis a los resultados estratificados por el grado de la lesión e índice de falla.

\footnotetext{
1,4-6 Trauma Surgeon, ${ }^{2,3}$ Resident

${ }^{1-6}$ Department of Trauma Surgery, Hospital João XXIII, Minas Gerais, Brazil
}

Corresponding Author: Camila Issa Azevedo, Trauma Surgeon, Department of Trauma Surgery, Hospital João XXIII, Minas Gerais, Brazil, Phone: 3195125352, e-mail: camilaiazevedo@yahoo.com.br
Materiales y métodos: Estudio prospectivo de los casos admitidos en el Hospital João XXIII, localizado en Belo Horizonte-Brasil, de enero de 2013 a diciembre de 2013. Los pacientes, víctimas de trauma hepático contundido, fueron admitidos en la sala de emergencia $y$, enseguida, divididos en dos grupos. Un grupo conteniendo los pacientes que cumplieron los criterios de tratamiento no operatorio y otro grupo formado por pacientes sometidos al tratamiento quirúrgico.

Resultados: Durante el periodo de este estudio, 47 pacientes fueron admitidos con trauma hepático contundido y 43 (91.4\%) de estos presentaron criterios de inclusión para el TNO. La tasa de falla del TNO fue de 9,3\%: 50\% de ellos presentaban lesión hepática grado II y 50\% lesión hepática grado V. Aquellos pacientes con lesión no hepática grado II que presentaron falla de TNO, también presentaban lesiones extra-hepáticas, ya aquellos pacientes con lesión hepática grado $\mathrm{V}$, la falla en el TNO se dio en consecuencia de sangramiento.

Conclusión: En centros de trauma, el tratamiento no operatorio se ha vuelto un tratamiento de escoja para pacientes con trauma hepático contundido. TNO en pacientes con lesión hepática grado $\mathrm{V}$ debe ser visto con cautela porque presentaron un mayor índice de falla relacionados a la propia lesión.

Palabras claves: Trauma, Lesión hepática, Tratamiento no operatorio, Laparotomía.

\section{INTRODUCTION}

Blunt abdominal trauma is an important cause of mortality among young adults. ${ }^{1}$ Advances in imaging modalities, such as ultrasound and computed tomography scan (CT), interventional radiology, critical care, and the introduction of damage control surgery during the past two decades have greatly influenced the diagnosis and treatment in trauma care. Hepatic trauma occurs in approximately $5 \%$ of all admissions in emergency room. ${ }^{2}$ Its prevalence has risen in the last three decades due to an increase in the number of cases and also as a result of an improvement in diagnostic methods. ${ }^{3,4}$ Management of blunt liver injuries has changed dramatically in recent decades.

The paradigm of nonoperative management (NOM) in adults was broken after the observation of the management of blunt splenic trauma in children. ${ }^{5}$ Nowadays, NOM of solid organs injury, such as liver, in stable patients, has been universally successful and is now the standard of care in trauma centers. ${ }^{6}$ There are many

Paper presented in research competition in the PTS Congress, Panama, 2014. 
doubts and questions concerning this type of treatment. World guidelines have no consensus about some aspects of this type of treatment, ${ }^{7}$ e.g. what is the definition of NOM failure?

A trained, cohesive and competent team is necessary to perform NOM. A well-designed protocol, patient follow-up and knowledge about the risk of possible complications are essential to understand the injury evolution. In environments where the conditions are not appropriated to perform NOM, surgical treatment is yet the best choice. Hospital João XXIII's protocol for NOM of blunt solid organs injuries was created in 2004 (Flow Chart 1). From November 2004 through to December 2013, 790 patients with blunt liver trauma were treated nonoperatively with success ratio of $95.7 \%$.

According to this protocol, the inclusion criteria for NOM of blunt hepatic injury are: hemodynamic stability

Flow Chart 1: Algorithm for nonoperative treatment of blunt abdominal trauma

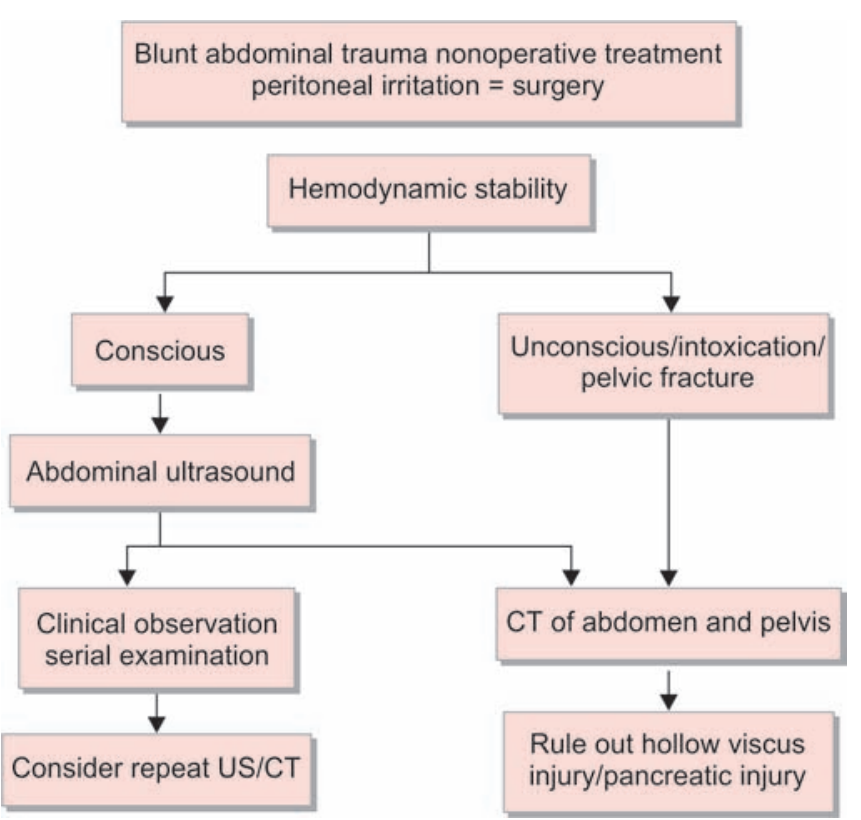

at admission or after two blood units transfusion, no signs of peritonitis and $\mathrm{CT}$ available at admission.

This study aims to analyze the outcomes of blunt hepatic trauma, and compare operative treatment (OT) and NOM, emphasizing the stratified results by grade of injury (Table 1) and failure rate.

\section{MATERIALS AND METHODS}

This is a prospective study of cases admitted to João XXIII Hospital, located in Belo Horizonte, Brazil. From January 2013 to December 2013, patients were admitted with blunt hepatic trauma on emergency room (ER) and were divided into two groups. One group contained patients who met the criteria for NOM and the other group was formed by patients with surgical indication.

The following data were analyzed: cause of injury, age, gender, revised trauma score (RTS), injury severity score (ISS), grade of injury according to the organ injury scale of the American Association for the Surgery of Trauma (OIS-AAST), associated abdominal injuries, complications, the need of surgical intervention, length of hospital stay and mortality.

Nonoperative management group was appropriately monitored and subjected to a rigorous clinical examination and at short time intervals. Patients were referred for surgical treatment in case of peritonitis or significant drop of the hematimetric hematocrit levels. Patients were discharged after eating normally, having regular bowel movements and in the absence of abdominal pain or fever. All patients were followed during 8 weeks. Follow-up TC were done in cases of injuries grades IV and V in order to evaluate injury healing.

\section{RESULTS}

During the study period, 47 patients were admitted with blunt liver injury and $43(91.4 \%)$ met the inclusion criteria

Table 1: Algorithm for nonoperative treatment of blunt abdominal trauma

\begin{tabular}{|c|c|c|}
\hline Grade & Type of injury & Description of injury \\
\hline \multirow[t]{2}{*}{1} & Hematoma & Subcapsular, $<10 \%$ surface area \\
\hline & Laceration & Capsular tear, $<1 \mathrm{~cm}$ parenchymal depth \\
\hline \multirow[t]{3}{*}{ II } & Hematoma & Subcapsular, 10 to $50 \%$ surface area \\
\hline & & Intraparenchymal $<10 \mathrm{~cm}$ in diameter \\
\hline & Laceration & Capsular tear 1 to 3 parenchymal depth, $<10 \mathrm{~cm}$ in length \\
\hline \multirow[t]{3}{*}{ III } & Hematoma & $\begin{array}{l}\text { Subcapsular, }>50 \% \text { surface area of ruptured subcapsular or parenchymal hematoma; } \\
\text { intraparenchymal hematoma }\end{array}$ \\
\hline & & $>10 \mathrm{~cm}$ or expanding \\
\hline & Laceration & $>3 \mathrm{~cm}$ parenchymal depth \\
\hline IV & Laceration & $\begin{array}{l}\text { Parenchymal disruption involving } 25 \text { to } 75 \% \text { hepatic lobe or } \\
1 \text { to } 3 \text { Couinaud's segments }\end{array}$ \\
\hline $\mathrm{V}$ & Laceration & Parenchymal disruption involving $>75 \%$ of hepatic lobe or $>3$ Couinaud's segments within a single lobe \\
\hline & Vascular & Juxtahepatic venous injuries, i.e. retrohepatic vena cava/central major hepatic veins \\
\hline
\end{tabular}


for NOM. All patients were stable at admission, with no signs of peritonitis and underwent CT. Data analyzed is shown in Table 2.

Grade II and III injuries were the most prevalent in NOM group; among patients referred to operative treatment (OT), grade II, III and V injuries were more common (Graph 1).

All patients with grade II and III injuries submitted to OT had associated lesions. Failure rate in NOM group was (4 patients) 9.3\%: 50\% of them had grade II injuries, and $50 \%$ had grade V. Patients with grade II injuries had also bowel lesions, and in those with grade $\mathrm{V}$, the failure was due to bleeding. Patients in whom NOM failed were operated and all of them survived.

The most common associated abdominal injuries in NOM group were: renal (27.9\%) (12 patients) and splenic (14.8\%) injuries. In this study, five patients (1.7\%) died-all due to associated extrahepatic lesions.

\section{DISCUSSION}

Since 1980, several studies have proposed that NOM of blunt liver injuries should be considered the standard of care for patients with hemodynamic stability. Careful patients selection undoubtedly influences the success of NOM. Advantages of NOM include lower hospital costs, reduced length of hospital stay (LOS), avoidance of nontherapeutic laparotomies and reduced transfusion risks. Recent studies have shown that the success rate of NOM of blunt liver injury is around $98 \%{ }^{8}$

Table 2: Comparison between patients of NOM and OT groups

\begin{tabular}{lll}
\hline Aspect evaluated & NOM & OT \\
\hline Mean length of hospital stay & 11 & 17 \\
Mean age & 26.8 & 28.8 \\
Major mechanism of injury & Motor vehicles & Motor vehicles \\
Gender & Male (76\%) & Male (87.5\%) \\
RTS & 7.85 & 6.8 \\
ISS & 21.82 & 30.2 \\
\hline
\end{tabular}

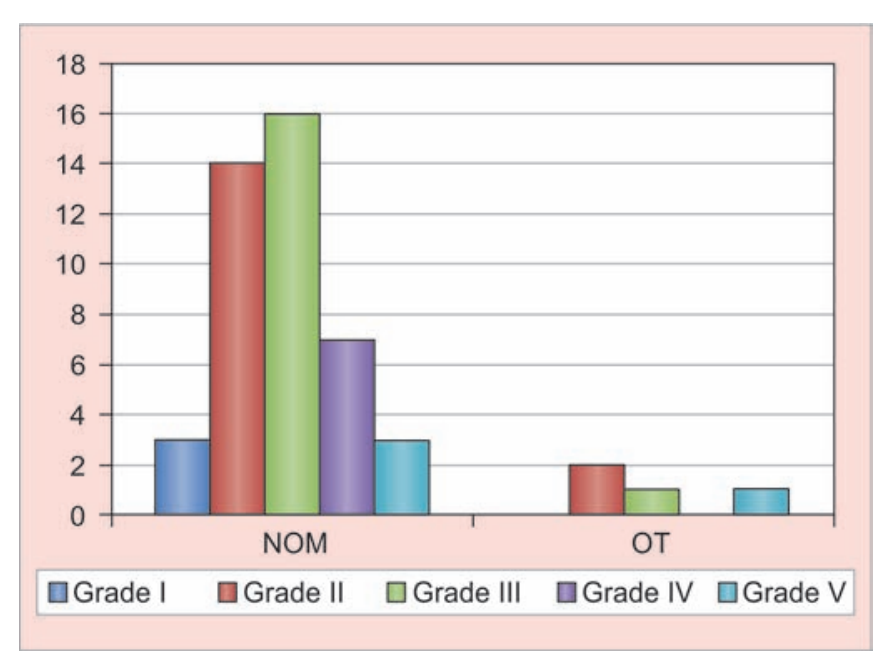

Graph 1: Distribution by grade of injury
In our study, failure rate of NOM group was $9.3 \%$. In low-grade injuries (I and II), failure was due to associated abdominal lesions. Furthermore, all patients who evolved with bleeding and hemodynamic instability had grade $\mathrm{V}$ injuries.

The decision to treat nonoperatively is influenced basically by the hemodynamic status of the patient, the grade of hepatic lesion, the presence of abdominal associated injuries and the neurological status. Meredith et al, in a study of 126 patients admitted with blunt hepatic trauma, showed an average grade of 2.6 on the AAST-OIS scale of liver injuries. ${ }^{9}$ That mentioned study demonstrated that $6.4 \%$ (3 patients) of patients had grade I liver injury, 34\% (16 patients) had grade II, 36.2\% (17 patients) had grade III, $14.89 \%$ (7 patients) had grade IV and $8.6 \%$ (4 patients) had grade V. Pachter et al demonstrated a predominance of grade II (31\%) and grade III (36\%) liver injuries. ${ }^{10}$ Grade II and III lesions were more prevalent in both groups (NOM and TO) in the present study (Graph 1).

In our study, the most frequent abdominal lesions associated with blunt liver injuries were renal (27.6\%) and splenic (14.8\%) injuries. Bynoe et al did not find abdominal injuries in patients with blunt hepatic trauma treated nonoperatively. ${ }^{11}$ In a retrospective study with 210 patients with blunt abdominal trauma, renal and splenic injuries were the most frequently abdominal lesions associated with hepatic injuries. ${ }^{12}$

Hepatic trauma occurred predominantly in males. This is in concordance with other published studies, as well as with the paradigm that men are more often exposed to traumatic injuries. ${ }^{12-14}$ The young population is the most affected, with an average age of 27 years for NOM and 29 years for OT, following the worldwide averages of 35, 32, 31 and 30 respectively in Germany, South Africa, Scotland and the USA. 15,16

Although they are considered complex injuries, grade III, IV and V lesions can be treated nonoperatively with excellent results. ${ }^{14}$ However, the current study as well as others in the literature showed that grade III injury acts similarly to grade I and II ones. ${ }^{14,17}$ Carillo et al showed similar results, with failure rate of $5 \%$ in grade III injuries, while grade IV had $51 \%$ of failure and grade V had $71 \% .{ }^{18}$

Complications due to the injury itself and failure in NOM are more frequent in grade $\mathrm{V}$ hepatic injuries. However, there are no scientific evidence that injury grade is a predictive factor for NOM failure in blunt hepatic injury. ${ }^{19,20}$ The most important criterion to treatment selection in blunt liver trauma is yet hemodynamic stability. ${ }^{21}$ Flow Chart 2 describes a useful algorithm for operative and nonoperative treatment of blunt abdominal trauma. 


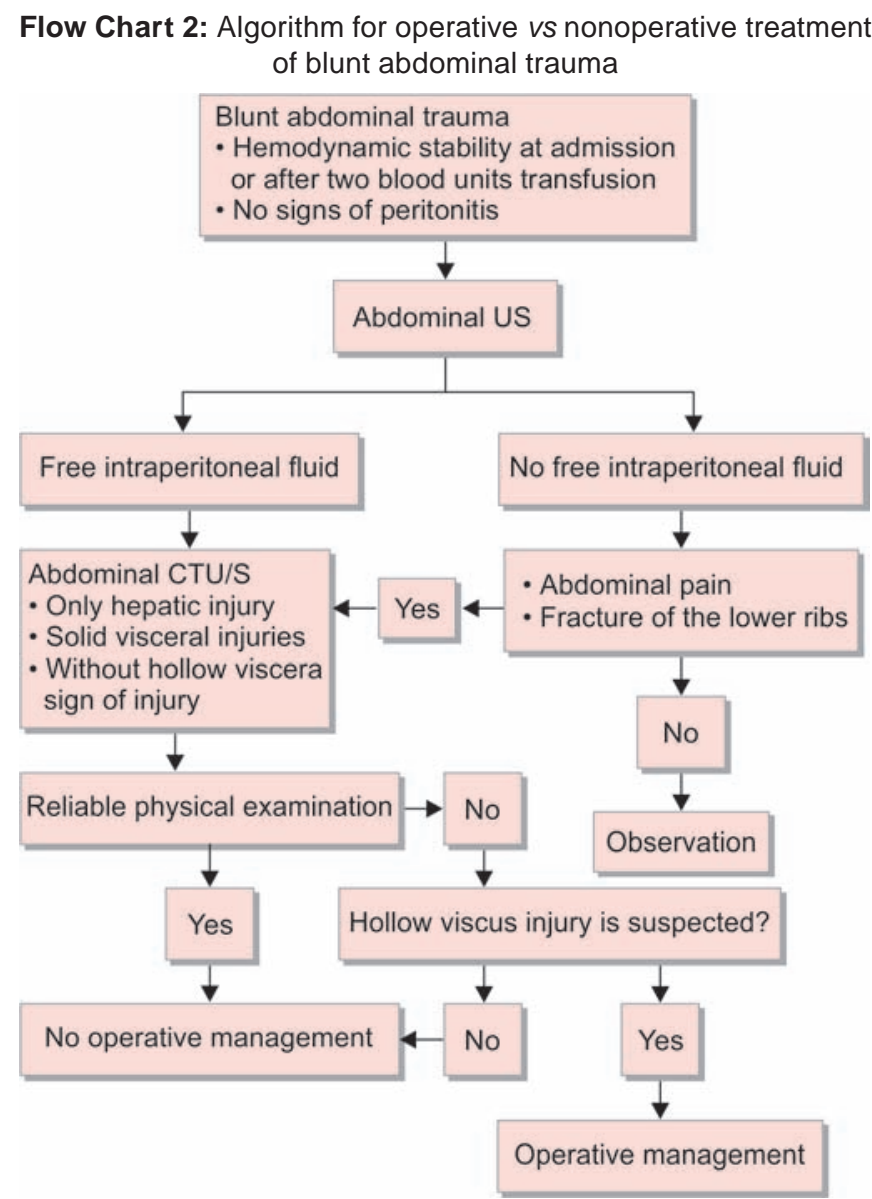

\section{CONCLUSION}

Nonoperative management has become the standard of care for patients with blunt liver injuries. However, as grade $\mathrm{V}$, injuries have a higher failure rate, they might receive special attention from the surgical team.

\section{REFERENCES}

1. Vukovic G, Lausevic Z. Diagnostics and treatment of liver injuries in polytrauma. Healthmed 2012;6(8):2796-2801.

2. Stracieri LD, Scarpelini S. Hepatic injury. Acta Cir Bras 2006;21(Suppl 1):85-88.

3. Velmahos GC, Toutouzas K, Radin R, Chan L, Rhee P, Tillou A, et al. High success with nonoperative management of blunt hepatic trauma: the liver is a sturdy organ. Arch Surg 2003;138(5):475-480.

4. Petrowsky H, Raeder S, Zuercher L, Platz A, Simmen HP, Puhan MA, et al. A quarter century experience in liver trauma: a plea for early computed tomography and conservative management for all hemodynamically stable patients. World J Surg 2012;36(2):247-254.

5. Upadhyaya P, Simpson JS. Splenic trauma in children. Surg Gynec Obstret 1968;126(4):781-790.
6. van der Wilden GM, Velmahos GC, Emhoff T, Brancato S, Adams C, Georgakis G, et al. Successful nonoperative management of the most severe blunt liver injuries: a multicenter study of the research consortium of new England centers for trauma. Arch Surg 2012;147(5):423-428.

7. Stassen NA, Bhullar I, Cheng JD, Crandall ML, Friese RS, Guillamondegui OD, et al Nonoperative management of blunt hepatic injury: an Eastern Association for the surgery of trauma practice management guideline. J Trauma Acute Care Surg 2012;73(5 suppl 4):S288-S293.

8. Trunkey DD. Hepatic trauma: contemporary management. Surg Clin North Am 2004;84(2):437-450.

9. Meredith JW, Young JS, Bowling J, Roboussin D. Non-operative management of blunt hepatic trauma: the exception or the rule? J Trauma 1994;36(4):529-534.

10. Pachter HL, Knudson MM, Esrig B, Ross S, Hoyt D, Cogbill T, et al. Status of nonoperative management of blunt hepatic injuries in 1995: a multicenter experience with 404 patients. J Trauma 1996;40(1):31-38.

11. Bynoe RP, Bell RM, Miles WS, Close TP, Ross MA, Fine JG. Complications of nonoperative management of blunt hepatic injuries. J Trauma 1992;32(3):308-314.

12. London JA, Parry L, Galante J, Battistella F. Safety of early mobilization of patients with blunt solid organ injuries. Arch Surg 2008;143(10):972-976.

13. Stein DM, Scalea TM. Nonoperative management of spleen and liver injuries. J Intensive Care Med 2006;21(5):296-304.

14. Coimbra R, Hoyt DB, Engelhart S, Fortlage D. Nonoperative management reduces the overall mortality of grades 3 and 4 blunt liver injuries. Int Surg 2006;91(5):251-257.

15. Moore EE, Cogbill TH, Jurkovich GJ, Shackford SR, Malangoni MA, Champion HR. Organ injury scaling: spleen and liver (1994 revision). J Trauma 1995;38(3):323-324.

16. Schluter PJ, Nathens A, Neal ML, Goble S, Cameron CM, Davey TM, et al. Trauma and Injury Severity Score (TRISS) coefficients 2009 revision. J Trauma 2010;68(4):761-770.

17. Polanco PM, Brown JB, Puyana JC, Billiar TR, Peitzman AB, Sperry JL. The swinging pendulum: a national perspective of nonoperative management in severe blunt liver injuries. J Trauma Acute Care Surg 2013;75(4):590-595.

18. Carillo EH, Reed DN Jr, Gordon L, Spain DA, Richardson JD. Delayed laparoscopy facilitates the management of biliary peritonitis in patients with complex liver injuries. Surg Endosc 2001;15(3):319-322.

19. Kozar RA, Moore FA, Cothren CC, Moore EE, Sena M, Bulger EM, et al. Risk factors for hepatic morbidity following nonoperative management: multicenter study. Arch Surg 2006;141(5):451-459.

20. Ochsner MG. Factors os failure for nonoperative management of blunt liver and splenic injuries. World J Surg 2001; 25(11):1393-1396.

21. Helling TS, Ward MR, Balon J. Is the grading of liver injuries a useful clinical tool in the initial management of blunt trauma patients? Eur J Trauma Emerg Surg 2009;35(2):95-101. 


\section{Blunt Hepatic Trauma: Suggested Algorithm for Surgical and Nonoperative Management}

In this prospective study, the authors present their experience over a year about the management of blunt hepatic trauma at the João XXIII Hospital in Brazil.

As demonstrated in this study, hemodynamically stable patients with liver injury from blunt abdominal trauma can be managed safely without celiotomy, regardless of injury severity. Nonoperative management (NOM) is the treatment of choice in this population. A $91.4 \%$ success rate was achieved in this study, attesting the safety of this approach.

Since there is no evidence-based consensus about some other topics of the NOM of blunt injuries of the liver, it is important to define the inclusion criteria for this strategy. It has not been possible to predict liver-related failures based on injury graded on computed tomography (CT) scan, hemoperitoneum or presence of associated injuries.

The authors decided the following criteria for the NOM: Hemodynamic stability at admission or two bloods of transfusion, no signs of peritonitis and CT available at admission. The rate of NOM failure in this study was 8.69\% similar to the one described by others in the literature. The current failure rate in adult blunt hepatic trauma is reportedly 0 to $19 \%$. The estimated amount of liver-related transfusion reported, ranges from 0 to 5 units, before considering an operative management in the recent literature.

From this study, we can conclude that NOM in patients with liver injury from blunt abdominal trauma should only be undertaken at institutions where there is adherence to the institutional guidelines, and the appropriate resources are readily available.

Maria Fernanda Jimenez Professor, Department of Surgery Hospital Universitario de Mederi Bogota, Colombia 